ture of a branch of astronomy which has been somewhat neglected in recent years. But some of the data on which von Niessl's conclusions are based are old and inaccurate. There is no doubt whatever that for the trustworthy investigation of various difficult questions affecting the sulject more exact, modern, and abundant observations are necessary.

\section{GEOLOGY OF THE WITWATERSRAND GOLD FIELD.}

THE Rand mining field is geologically one of the most interesting areas in South Africa, as well as the most important economically. Its general structure has been gradually unravelled by the work of the geologists and miners of the Transvaal, and it has now been investigated in detail by the Geological Survey of South Africa. The results of this survey are shown on an excellent map (Geological Map of the Witwatersrand Gold Field, 3 sheets, I9I7) on the scale of $\mathrm{I}$ to 5000 , or almost an inch to the mile. It has not been contoured owing to the inadequacy of the topographic surveys, but as the mining fields are on an area of high plains this deficiency is of little practical inconvenience. The map is mainly the work of Mr. E. T. Mellor, who has prepared also a short explanation of 46 pages summarising the geology of the mining field and including a bibliography of the chief literature. The report classifies the rocks and gold reefs of the Rand. The age of the rocks is so uncertain that no precise correlation with those of Europe is attempted. They are divided into three systems with South African names. The youngest, the Karroo, which includes the famous Dwyka glacial deposits and the coal seams, has yielded many fossils, so that its correlation is at least approximately known. The Transvaal system includes the quartzites to the north of the goldfield, a thick series of dolomites and cherts, and the Black Reef series. The oldest of the three, the Witwatersrand system, includes the quartzites, shales and conglomerates of the goldfield. These two older systems are unfossiliferous, and whether they are Lower Palæozoic or pre-Palæozoic is uncertain. The author accepts the view that the gold of the Rand is of alluvial origin, and abandons the long popular theory that it was introduced by infiltration as in ordinary lodes. The alluvial or placer theory has been advocated by several geologists, while the majority of the mining engineers have supported the infiltration theory. Probably the most striking feature displayed by the map is that strike-faulting is far more important than had been suspected. The author concludes that the unworked parts of the goldfield are so extensive that the gold-mining industry has elements of "comparative permanency not found in many other goldfields and more akin to those of a base metal district or a manufacturing centre."

\section{ORGANISED KNOWLEDGE AND NATIONAL WELFARE. 1}

THE future of any nation is secure if it lives up to its possibilities. The nation which does this is bound to be a leader among nations and to command world-wide respect. Its national problems will be solved, and solved intelligently and thoroughly. The greatness of a man is in part born in him and in part the product of his environment. According to eminent. biologists, he is about two-fifths born and three-fifths made. Similarly, a nation is great according to its

1 Abstract of an address given on April g to the Associated Engineering Societies of Worcester, Mass., by Dr. P. G. Nutting. Reprinted from Science of September 14 .

NO. 2504 , VOL. IOO] resources and according to its development of these resources. And the development of those resources may be accomplished only through organised knowledge.

(I) The Function of Organised Knowledge.-Consider for a moment two manufacturing concerns on an. equal footing as regards output, but of which one is continually making progress through improvements in manufacturing processes, developing new and valuable products and investigating the fundamental principles underlying all these processes. This firm will in time outstrip the other in every way; the balance, in fact, is a very delicate one, since the results are cumulative. In quite a similar manner, that nation will advance to leadership in which the increase in organised knowledge and the application of that knowledge are greatest. For this reason, interest in research should be as wide as the nation and should cover the whole gamut of problems from administration to agriculture, from medicine to manufacture. For it is only through the solution of individual problems that general principles can be arrived at and the sum total of useful organised knowledge increased.

It is essential that the wide field to be covered be kept in mind, extending over not only physics, chemistry, engineering, and all their branches, but all the biological and mental sciences as well. In the last analysis an increase in knowledge in the field of the biological sciences means more and better food, improved racial stock, and improved public health, as well as increased material welfare in all having to do with plants and animals. Increased knowledge of the fundamental principles of the mental sciences means increased efficiency in administration, legislation, education, operation, and research. I do not mean mere book learning in psychology, but such a command of the fundamental principles as will assist in the solution of all practical problems. Increased knowledge of chemistry means increased ability to utilise raw materials and an improvement in general health and living conditions. One may almost say that the generalised problem of chemistry is to convert the less expensive raw materials, such as cellulose, petroleum, glucose, various minerals and oils, starch, nitrogen of the air and the like, into food, clothing, tools for our use, and means for national defence. An application of the fundamental principles of physics in the way of various engineering problems leads to a fuller utilisation of resources and of new products useful to man, makes inventions possible and effective, and adds to the general increase in operating efficiency in every way.

The utilisation of organised knowledge in national welfare comes about both through knowledge itself and the incentive to apply that knowledge. Both ability and incentive are essential to utilisation. So far as knowledge went, we might have made dyes and optical glass many years ago in the United States, but since they could be bought so cheaply there was no incentive to develop the manufacture of such articles. These are cases of ability without incentive. On the other hand, there has long been an incentive for the fixation of nitrogen and for various mechanical devices, but these have not been forthcoming for lack of sufficient knowledge.

In general, in normal times it is perhaps no exaggeration to say that neither the average individual nor the average nation approaches within 50 per cent. of their possibilities. Nothing short of a war threatening the national existence can shake a nation out of its lethargy. Similarly, the average individual cannot be induced to put forth his best efforts without the strongest of incentives. It is unfortunate that this is the case. However, with sufficient attention given to the problem by trained experts in mental science, it is 
quite possible that at some future date as high as 60 or so per cent. of the possibilities may be realised without any appeal to arms for the nation or any unusual incentive for the individual.

(2) The Increase of Organised Knowledge.-The research by which organised knowledge is increased will doubtless always be carried on chiefly by three distinct types of research organisations: research by the Government in national laboratories, research by the universities in connection with the work of instruction, and research by industrial laboratories in connection with the interests of manufacturing concerns. Apart from these three main classes of laboratories there will always be large, privately endowed research organisations, dealing with neglected fields of remote commercial interest, private industrial laboratories supported by consulting fees, and co-operative testing laboratories, also self-sustaining.

National, university, and industrial research follow three essentially different lines. There is considerable overlap in field, it is true, but each is centred on a different kind of research. The proper function of national research is the solution of such problems as concern the nation as a whole, affecting the general interests of all classes of individuals; it is the custodian of standards, it develops methods of precise measurements and investigation, it is trouble engineer for the solution of very difficult problems or the problems of producing units so small as not to be able to have their own research laboratories. It is the proper guardian of the public health. It solves problems connected with contagious and vocational diseases. It develops methods of making good roads, increasing the fertility of the soil, and stocking waters with fish. National research is of all grades, from that dealing with fundamental principles up to that relating merely to lessening the costs of production.

University research must always, in the very nature of things, be concerned chiefly with the advancement of the various sciences as such, and with the development of the fundamental principles of each science. The best university instruction is along these lines, and investigators and students in close touch with them will naturally have most new ideas in close connection with fundamental principles. University research is necessarily one of small jobs and the best minds, and is without very much continuity. The advanced student is interested in a research just long enough to make it acceptable as a doctor's thesis. The instructor is too burdened with teaching to give more than a margin of time to research. But a very small part of the university research is extended year after year, covering a wide field. This is quite as it should be, the university looking after those fields of research of little commercial value on one hand, and not directly affecting the interests of the nation as a whole on the other, but of fundamental and farreaching importance to all.

Industrial research takes the middle ground and has already become a distinct profession. It is in close touch with practical commercial application on one hand, and with fundamental principles on the other. Its proper field is anything between elimination of works troubles and the investigation of fundamental principles. The staff of the ideal industrial rescarch laboratory is composed of experts of wide experience who can serve the manufacturing departments in a consulting capacity without sacrifice of time. We may perhaps best summarise the preceding statements by describing the ideal research man and the ideal research laboratory.

Some writers have spoken of the investigator as a rare individual to be sifted out from educational institutions with great care for a particular line of work. My personal opinion is that a large percentage of the NO. 2504 , VOL. IOO] men students are fitted for research work if properly started along the right line. The investigator should have a mind at once fertile and well-trained. His mind should be teeming with new ideas, but he should possess unerring judgment to reject those which are not logical or promising. We are often asked what sort of preparation in physics would be best for men intending to take up research as a life work. It has even been proposed to give courses in "applied physics" for the benefit of those intending to take up industrial research. Our invariable reply is that the best preparation for a research man is a thorough grounding in the fundamental principles of his science : physics, chemistry, or whatever it may be. If he has this thorough knowledge of fundamental principles it is safe to say that in any properly organised research laboratory with the proper leadership and companions, such a student will have many times as many useful ideas as he can himself possibly follow up with research. Scarcely anyone who has completed advanced work in a science can read, say, a journal of abstracts without thinking of many problems which he would like to investigate. Fertility of mind is not so much an inborn quality of the mind itself as of the training and association which that mind has had.

The ideal industrial research organisation may perhaps be outlined with a knowledge of its development during the last fifteen years. I shall give, frankly, my personal views on the matter, based on an intimate knowledge of four universities, three professional research laboratories, and a visiting acquaintance, so to speak, with quite a number of others. The ideal in. dustrial laboratory, to my mind, consists of two quite distinct divisions: one taking the brunt of works troubles and testing or making analyses of the material used. The other wing is complementary to this, and deals with the larger fundamental problems encountered, problems requiring skilled specialists and considerable time for their solution. The alternative organisation with a single research laboratory covering both works troubles and fundamental problems is not so successful. The plan in this case is to have considerable research in progress of very little interest to the company, but engaging a staff much larger than required to take care of ordinary works troubles. In this case, when works troubles are many and insistent, as they are wont to be at times. the staff engaged upon fundamental research forms a reserve to be called out occasionally to deal with works troubles. The chief disadvantage of this is that the fundamental work is subject to more or less frequent interruption and cannot be so efficiently carried on. On the other hand, when the research is in two quite distinct divisions, fundamental work is not subject to interruption by works troubles.

Industrial research is pre-eminently fitted to be carried on by team work. This we have developed to a high degree in Pittsburg, and consider very much more efficient than the alternative cell system, where each leading man has a room or suite of rooms to himself and keeps his work to himself. In the ideal organisation two or three men work together on the same large problem or group of problems, the aim being to have a good theoretical man and a good experimentalist working together as much as possible, or even a physicist and chemist in some cases. The characteristic of the team-work plan, however, is the conference system. The five or six men most interested in each line of research meet for an hour each week to discuss the problem in its various aspects, to plan new work, and to consider various interpretations and applications of the results obtained. The ideal conference is not fewer than four and not more than eight men, and includes an efficient stenographer. To one experienced in such team work the results of 
getting together are surprising. A good suggestion is no sooner made than capped by a better, and the saving in time and effort is almost incalculable.

The conference system also aids in putting useful results before the other wing of the research division and before the patent department. At each of our conferences are representatives of the other wing of the research division, charged with taking up any results immediately applicable, and a member of the legal department who takes care of any ideas worth patenting. This plan of conferences relieves the scientific men from responsibility for directing the attention of the works or of the patent department to useful patentable results.

So far as national welfare is concerned, in order to increase our stock of organised knowledge we need more teaching by professors and instructors in closer touch with industrial problems. So far as developing research men goes, the ideal instructor is probably an ex-professional research man, and, in many cases, one who has made a reputation or a fortune by his work along industrial lines. Another need is, of course, more research laboratories all along the line. The increase would naturally be among industrial organisations and the expense borne largely by manufacturing concerns, since it is they who reap the chief direct financial benefit.

Another great need is co-operation among the various branches of research : national, university, and industrial. There should be a free interchange of men between such laboratories, and each should be thoroughly familiar with the needs and problems of the other. One great benefit from this war, if it lasts sufficiently long, will be to force co-operation between different branches of research.

(3) The Application of Organised Knowledge.-The present national crisis brings home to us the crying needs of the nation in availing itself of the knowledge and ability at its command. Fifty thousand specialists, in applying scientific knowledge to practical problems, as well as scores of research laboratories, have offered their services to the nation. But problems requiring investigation are slow in being developed. Once they are formulated and given to the engineers of the country, few will remain unsolved very long.

It is for the engineer to apply the results of research to practical problems and to carry practical problems demanding general research back to the research laboratories. To the engineer every special problem requires a special application of fundamental principles. Is it too much to hope that the day is rapidly approaching when all great problems, particularly those of our national and State Governments, will be automatically placed in the hands of trained specialists? Not self-seeking politicians, or yet men with mere theories, but engineers with a real command of fundamental principles, men with an unbroken record of big achievements and no failures, men ever ready to stake their all on their ability to handle problems in their specialty.

Prof. Joseph Le Conte, in an address years ago, remarked that each of the great professions first attained high standing when it was taught as such in universities. When so taught, the professional men turned out are no longer quacks, but each has a real command of the fundamental principles in his chosen field of action. The basic relation is that any profession has standing in so far as its fundamental principles have been developed and applied. To retain standing, a profession must be continually increasing its stock of knowledge of fundamental principles through research. The engineer of standing in his profession must not be content with a mere working knowledge of rules of thumb, but must have a real command of basic prinNO. 2504, VOL. IOO] ciples in his chosen field and in related fields. The illuminating engineer, for example, should not only know lighting, but also possess a working knowledge of the laws of vision and of geometrical and physical optics. So the great physician or constructional engineer has a command of his own field and an intimate acquaintance with related fields.

So also with research as a profession, the leaders have not only a taste for research and logical minds clearly to analyse and attack problems with thorough scientific knowledge, but also a knowledge of the principles of research; getting the most out of their own minds, avoiding side-issues, co-operating with their colleagues, and putting their most valuable results in permanent, readily available form. Research is one of the youngest of the professions, and one with a promising future, but let no one enter it without thorough knowledge or a full understanding of its aims and methods. With sufficient attention given to research and to its application, this nation with its great national resources should at once attain and retain a permanent lead among the nations of the earth.

\section{UNIVERSITY AND EDUCATIONAL INTELLIGENCE.}

Sir William Tatem has given $25,000 l$. for a laboratory at the University College of South Wales, Cardiff.

WE notice with regret that Mr. Bonar Law announced in the House of Commons on October I9 that he feared it would be possible neither to pass the Education Bill this session, nor to give a day for the second reading, unless there was a prospect of passing the Bill. There is little substantial opposition to the essential clauses of Mr. Fisher's Bill, and all the provisions covered by them are "urgently demanded by, and connected with, the circumstances of the war," as Mr. Fisher has said. We trust that even yet the Government may be able to proceed with the Bill.

THE University of Bristol has again benefited from the generosity of the Bristol family of Wills and their interest in higher education. Mr. Henry $\mathrm{H}$. Wills lately purchased the Royal Fort House and grounds, which immediately adjoin the University buildings. This historical house was built and decorated in the eighteenth century by a member of the Tyndale family, descendants of William Tyndale, translator of the Bible. The greater part of this property, as well as some adjoining land, has been conveyed by Mr. Wills to the University for future extensions. 'The property conveyed covers nine acres, which will give the University a total building area of about thirteen acres. Part of the new site has been marked out for the purpose of the department of physics, and another part for that of a residential college. It is proposed to retain the existing house as part of the group of buildings which will eventually occupy the site. It will be remembered that shortly before the war Mr. H. H. Wills, jointly with his brother, Mr. George A. Wills, placed a sum of more than $200,000 l$. in the hands of the University for the construction and endowment of buildings on another part of its site.

THE governors of the Huddersfield Technical College are appealing for public support to enable them to carry out a large extension of the existing buildings. For many years the college has been seriously overcrowded, whilst in some important branches of local industries, such as woollen carding and spinning, no provision whatever has been made for technical instruction. The chemical and engineering industries of the district are developing so quickly that the need for better accommodation at the Technical College has become very urgent. The scheme contemplates the 